\title{
Sobre Antonin Artaud y Platón
}

\author{
About Antonin Artaud and Platon \\ Juan Carlos Sánchez LeÓN \\ Universidad de Jaén
}

\begin{abstract}
RESUMEN ABSTRACT
Este artículo analiza la influencia de la filosofía de Platón en la metafísica de la crueldad desarrollada por Antonin Artaud entre 1932 y 1936, especialmente en los manifiestos del «Teatro de la Crueldad»

(1932-1933). Artaud muestra un gran interés en temas filosóficos platónicos y neoplatónicos como la teoría de las Ideas, el mito de la Atlántida, la figura de Eros y

la visión de los cultos mistéricos, los dioses y los daimones, temas que influyeron en su concepto de crueldad.

PALABRAS CLAVE: Platón, Antonin Artaud, Crueldad, Filosofía griega, Tradición clásica.

This paper analyses the influence of Plato's philosophy on the metaphysics of cruelty developed by Antonin Artaud between 1932 and 1936, specially in the manifestos of the "Theatre of Cruelty" (1932-1933). Artaud shows a great interest in platonic and neoplatonic philosophical subjects as the Ideas theory, the Atlantis myth, the figure of Eros and the notion about Mistery cults, gods and daimones, themes which influenced his concept of cruelty.

KEYWORDS:

Plato, Antonin Artaud, Cruelty, Greek philosophy, Classical tradition.
\end{abstract}

La filosofía arcaica griega, considerada de forma esotérica, es sin duda uno de los fundamentos de la metafísica de la «crueldad» cósmica de Artaud, desarrollada por el autor durante los años treinta del siglo XX, especialmente en sus «Manifiestos» sobre el «Teatro de la Crueldad». Heráclito, Platón, Pitágoras, Filón, filósofos neoplatónicos como Plotino, Yámblico, Porfirio y el emperador Juliano, y filósofos neopitagóricos como Apolonio de Tiana, son citados por el dramaturgo en obras mayores como El Teatro y su Doble (1938), Heliogábalo o el Anarquista coronado (1934) o Los Tarahumaras (texto inicial de 1936-1937). Pero también hay referencias a la filosofía griega arcaica en escritos menores y en la correspon- 
dencia de Artaud durante los años treinta (Oeuvres complètes, XXVI tomos, edición revisada y aumentada, París, Gallimard, 1970-1994 = O.C.). Se trata aquí de establecer el dossier sobre Artaud y Platón.

El dossier sobre Platón y Artaud se compone de los siguientes documentos:

- Referencia al mito de la caverna y a la teoría de las ideas de Platón ( $L a R e-$ pública, libro VII) en «La Mise en scène et la Métaphysique», conferencia pronunciada por Artaud en la Sorbona el 10 de diciembre de 1931 (publicada en la Nouvelle Revue Française, . $^{\circ} 221,1$ de febrero de 1932, texto que forma parte de El Teatro y su Doble, 1938). Artaud describe y analiza aquí la teatralidad del cuadro de Lucas de Leyde «Las hijas de Lot», Ilegando incluso a crear una nueva "puesta en escena» del tema (en el curso de una visita al Louvre, en septiembre de 1931, Artaud había observado un parecido entre este cuadro y el teatro balinés: carta del 6 de septiembre a Jean Paulhan = O.C. V, 55): «Parece que el pintor haya tenido conocimiento de ciertos secretos concernientes a la armonía lineal, y de medios para hacerla actuar directamente sobre el cerebro. En todo caso, esta impresión de inteligencia repartida en la naturaleza exterior, y sobre todo en la forma de representarla, es visible en otros detalles de la tela, por ejemplo este puente de la altura de una casa de ocho pisos levantado sobre el mar, y en el que algunos personajes, uno tras otro, desfilan como las Ideas en la caverna de Platón» (O.C. IV, 34).

- Referencia al mito platónico de la Atlántida (Timeo, Critias) en el texto "Galápagos, les îles du bout du monde», aparecido en los números 59 y 60 de la revista Voilà, 7 y 14 de mayo de 1932: «Estas islas han visto un aire y un cielo que han debido respirar los Atlantes $u$ otros pueblos antiguos, de raza compuesta de hombres [compuestas de razas de hombres, según la sugerencia de la edición Gallimard] infinitamente más profundos y más sabios que nosotros» (O.C. VIII, 27).

- Referencia general a Platón y a su visión de los cultos mistéricos (Misterios Órficos y Misterios de Eléusis) en «Le Théâtre alchimique», escrito que forma parte de El Teatro y su Doble (1938) y que fue publicado por primera vez en Buenos Aires, traducido a castellano y firmado por Artaud en septiembre de 1932, en la Revista Sur, con el título de El Teatro alquímico (n. ${ }^{\circ}$ 6 , otoño 1932, año II). La redacción de este texto, que había sido solicitado a Artaud por Jules Supervielle, parece haber comenzado hacia el 15 de marzo de 1932 (ver fragmento XVII del Dossier sur le Théâtre et son Double, p. 227, y en el tomo V, el Post-scriptum a la carta escrita hacia el 20 de marzo a Jean Paulhan); el manuscrito fue remitido a Supervielle hacia el 15 de mayo de 1932, según la edición Gallimard (O.C. IV, 290). Artaud escribe: «Los Misterios Órficos que subyugaban a Platón debían poseer, en el plano moral y psicológico, un poco de este aspecto trascendente y definitivo del 
teatro alquímico, y, con elementos de una extraordinaria densidad psicológica, evocar en sentido inverso símbolos de la alquimia, que proveen el medio espiritual de decantar y de transfundir la materia, evocar la transfusión ardiente y decisiva de la materia por el espíritu. Se nos dice que los Misterios de Eléusis se limitaban a poner en escena un cierto número de verdades morales. Creo, más bien, que debían de poner en escena proyecciones y precipitaciones de conflictos, luchas indescriptibles de principios, tomadas bajo este ángulo vertiginoso y resbaladizo en el que toda verdad se pierde realizando la fusión inextricable y única de lo abstracto y de lo concreto, y pienso que a través de músicas de instrumentos y de notas, de combinaciones de colores y de formas, de las que hemos perdido hasta la idea, debían, por una parte: llenar esta nostalgia de la belleza pura de la que Platón ha debido encontrar en este mundo, por lo menos una vez, la realización completa, sonora, chorreante y escueta; y, por otra parte: resolver mediante conjunciones inimaginables y extrañas para nuestros cerebros de hombres aún despertados, resolver o incluso aniquilar todos los conflictos producidos por el antagonismo de la materia y del espíritu, de la idea y de la forma, de lo concreto y de lo abstracto, y fundir todas las apariencias en una expresión única que debía ser parecida al oro espiritualizado» (O.C. IV, 50).

- Referencia al Eros platónico (Banquete) en «Le Théâtre et la peste», conferencia pronunciada por Artaud en la Sorbona el 6 de abril de 1933 (publicada en la Nouvelle Revue Française, $n .^{\circ} 253,1$ de octubre de 1934, escrito que forma parte de El Teatro y su Doble, 1938): «Se puede decir ahora que toda libertad verdadera es negra y se confunde indefectiblemente con la libertad del sexo que es negra también sin que se sepa muy bien por qué. Pues hace mucho tiempo que el eros platónico, el sentido genésico, la libertad de vida, ha desaparecido bajo el revestimiento sombrío de la libido que se identifica con todo lo que hay de sucio, de abyecto, de infamante en el hecho de vivir, de precipitarse con un vigor natural e impuro, con una fuerza siempre renovada hacia la vida» (O.C. IV, 30). Hay una referencia contemporánea al Eros y al Banquete de Platón, suprimida en el manuscrito original, en el ensayo Héliogabale ou l'anarchiste couronné, texto escrito en 1933 y publicado el 28 de abril de 1934: «No es menos cierto que el amor es función de nuestro distanciamiento de las cosas, y este distanciamiento que es una gracia sólo estalla en almas excepcionalmente favorecidas. $Y$ además el Amor como la Voluntad es una fuerza de la que es falso creer que seamos libres para disponer. Esta fuerza que no se parece a ninguna otra, y que sólo existe diferenciada, sí, diferenciada, es el único medio que tenemos de unirnos a la vida cósmica, y no es por nada que Platón emplea todo un libro para describirnos la vida de Eros» (O.C. VII, 407 n.45).

- Referencia a Platón y a los filósofos neoplatónicos Yámblico y Juliano emperador, y a su visión de los dioses, en el ensayo Héliogabale ou l'Anarchiste couronné, texto escrito en 1933 y publicado el 28 de abril de 1934: 
«Platón habla de la naturaleza de los dioses, los identifica con principios, sin permitirnos para esto ver más claro en estos principios que son fuerzas y en estas fuerzas que son dioses. Le preguntaron a Yámblico para saber por qué el sol y la luna, que son dioses, son visibles, cuando los dioses no tienen cuerpo. Y he aquí lo que Yámblico responde en el Libro de los Misterios: «Los dioses no están contenidos en los cuerpos, pero sus vidas y sus acciones divinas los contienen; no están vueltos hacia el cuerpo, pero los cuerpos que ellos contienen están vueltos hacia la causa divina». Son las capas groseras de la población las que han creado los dioses que se nos arroja a la cabeza y si... fueramos capaces de comprender a Platón como debe ser comprendido, podríamos, por el camino del esoterismo antiguo, remontar hasta una noción de dioses-principios que no hay que confundir con las figuraciones antropomorfas de los dioses» (O.C. VII, 52-53; es probable que Artaud aluda a la larga exposición de Platón sobre la naturaleza del mito y sobre los dioses de La República II y III, nos. 377-392); «Pues se puede pensar que tan cerca de los misterios antiguos y sobre la línea de aspersión de los Taurobolos, los personajes que eran puestos en escena de esa manera, no debían comportarse como frías alegorías sino que, significando fuerzas de la naturaleza, las que corresponden al círculo interior del sol, el segundo sol según Juliano, el que está entre la periferia y el centro, -y se sabe que sólo el tercero es visible-, debían conservar una fuerza de puro elemento» (O.C. VII, 93). Yámblico, filósofo griego neoplatónico nacido en Calcis hacia 283, muerto hacia 333, estudió las doctrinas de Platón y de Pitágoras, y también las de los Caldeos y Asirios. Influyó notablemente en el desarrollo del neoplatonismo plotiniano y porfiriano, acentuando los motivos religiosos y teológicos, al pensar que el hombre podía entrar en contacto con la divinidad mediante ritos secretos, misterios e iniciaciones. Dentro del neoplatonismo, llevó a cabo una extraordinaria multiplicación de los grados ideales, sistematizando dioses, ángeles, demonios y héroes de la tradición religiosa y mitológica, con ayuda del sistema matemático simbólico de los neopitagóricos. Según la edición Gallimard, la cita textual de Yámblico está sacada de la primera parte de Los Misterios de los Egipcios, de los Caldeos y de los Asirios, traducido en 1895 por P. Quillard. Flavio Claudio Juliano, emperador filósofo, discípulo de Yámblico, nació en Constantinopla en 331 y murió en Persia en 363. Había sido instruido en la cultura pagana, en secreto, por el eunuco Mardonius, después prosiguió sus estudios en Constantinopla con el rétor Libanio. Se orienta hacia el neoplatonismo y favorece el culto al Sol. Cuando se convirtió en emperador, intentó restablecer el paganismo, a cuyas doctrinas religiosas y filosóficas buscó dar una vía nueva incorporando las tendencias que contribuían al éxito del cristianismo: el altruismo, la caridad, la simplicidad de costumbres.

- Referencia general a Platón y a su visión de los dioses, en la crítica que hace Artaud a su propia tragedia Les Cenci, en una reseña de Le Figaro, 5 
de mayo de 1935, poco antes de la representación de gala: «Y es porque Los Cenci son un Mito, por lo que este tema, transportado al teatro, se ha convertido en una tragedia, y no en un drama; pues aquí los hombres son más que hombres, si es que no son todavía dioses. Ni inocentes ni culpables, están sometidos a la misma amoralidad esencial de estos dioses de los Misterios Antiguos de donde ha salido la tragedia. ¿Qué eran los dioses para los Antiguos? Hay en Platón páginas y páginas para discutir sobre la naturaleza de los dioses. Sea como fuere, estos dioses iban derechos fuera de nuestras pequeñas distinciones humanas en las que todo se separa entre el mal y el bien, como si el mal no fuera traicionar su naturaleza y el bien quedarse ligado a él, cualesquiera que sean las consecuencias morales de las que los dioses nunca se han preocupado. He intentado conservar a los personajes de mi tragedia esta especie de amoralidad fabulosa que pertenece al rayo que golpea, como a las efervescencias de una ola gigante desencadenada. Y me ha aparecido que en una época como ésta, en la que la naturaleza habla más alto que los hombres, había que resucitar un viejo mito que tocase en lo vivo de las inquietudes de hoy» (O. C. V, 40-41; al igual que en la referencia anterior, O.C. VII, 52-53, es probable que Artaud aluda a la larga exposición de Platón sobre la naturaleza del mito y sobre los dioses de La República II y III, nos. 377-392).

- Referencia general a Platón y al filósofo neoplatónico Juliano emperador, y a su visión de los dioses, en "Le Théâtre et les dieux», texto aparecido en castellano en el diario El Nacional de México el 24 de mayo de 1936 («El Teatro y los dioses», traducción de J. Ferrel; original francés de Artaud fechado y firmado el 29 de febrero de 1936): «Ahora bien, yo digo que la vida debe revivir en la metafísica. Y esta actitud difícil, que enloquece a la gente de hoy, es la actitud de todas las razas puras que siempre se han sentido al mismo tiempo en la muerte y en la vida. Es por lo que la cultura no es escrita, y que, como dice Platón: «el pensamiento se ha perdido el día en que la palabra se ha escrito". Escribir es impedir al espíritu moverse en medio de las formas como una vasta respiración. Porque la escritura fija el espíritu y lo cristaliza en una forma, y, de la forma, nace la idolatría. El verdadero teatro, como la cultura, nunca ha sido escrito» (O.C. VIII, 165); ««Hay tres soles, decía el emperador Juliano, de los cuales sólo el primero es visible». Y Juliano el Apóstata no es sospechoso de adentrarse en la espiritualidad cristiana, él que es uno de los últimos representantes de la CIENCIA de los Antiguos» (O.C. VIII, 162).

- Referencia al Diálogo de Platón Critias y al mito de la Atlántida en relación con el ritual de los indios Tarahumaras, en el artículo «Le rite des rois de l'Atlantide", aparecido en castellano en el diario mexicano El Nacional el 9 de noviembre de 1936 («El rito de los reyes de la Atlántida», original francés perdido) después de que Artaud hubiera dejado México; artículo que forma parte de Los Tarahumaras (texto inicial de 1936-1937). Escribe Artaud: 
«El 16 de septiembre, día de la fiesta de la Independencia de México, he visto en Norogachic, en el fondo de la Sierra Tarahumara, el rito de los reyes de la Atlántida tal y como Platón lo describe en las páginas del Critias. Platón habla de un rito extraño al que se libraban los reyes de la Atlántida en circunstancias desesperadas para su raza. Aunque tenga algo de mítica la existencia de la Atlántida, Platón describe a los Atlantes como una raza de origen mágico. Los Tarahumaras, que son para mí los descendientes directos de los Atlantes, continúan consagrándose al culto de los ritos mágicos... Así pues, para volver a Platón y a las verdaderas tradiciones esotéricas que manifiestan sus obras escritas, he visto en la Montaña Tarahumara el rito de estos reyes quiméricos y desesperados. Platón cuenta que a la puesta del sol los reyes de la Atlántida se reunían ante un toro sacrificado. $Y$ mientras que algunos sirvientes cortaban el toro en trozos, otros recogían los trozos cuya sangre vertían en copas. Los reyes bebían esta sangre y se emborrachaban cantando una especie de melodía lúgubre hasta que no quedaba en el cielo más que la cabeza del sol moribundo y en la tierra sólo la cabeza del toro sacrificado. Entonces, los reyes se cubrían la cabeza de cenizas. Y su melodía lúgubre cambiaba de tono a la vez que iban cerrando el círculo que formaban. Toda invocación al sol se convertía en una especie de reproche amargo, tomaba el aspecto de una contrición pública, la forma de un remordimiento que los reyes expresaban de común acuerdo hasta el momento en que la noche caía completamente. Este es el sentido del rito descrito por Platón. Ahora bien, un poco antes de que el sol se pusiera sobre Norogachic, los Indios condujeron un buey a la plaza de la aldea $y$, después de haberle atado las patas, comenzaron a desgarrarle el corazón. La sangre fresca era recogida en grandes jarras. No olvidaré fácilmente el rictus de dolor del buey cuando el cuchillo del Indio le desgarraba las entrañas. Los bailarines matadores se agruparon delante del toro y cuando éste hubo muerto comenzaron sus danzas...delante de esta carnicería, y era en verdad un espectáculo extraño el ver a dos Indios sobre el toro muerto, haciendo brotar la sangre y cortar los trozos a golpe de hacha... Danzaron así hasta la puesta del sol, y mientras bailaban otros Indios recogieron trozo a trozo el cuerpo del toro, del que abandonaron la cabeza en el suelo en el mismo momento en que la cabeza del sol caía en el cielo. Entonces los jefes de danza se pararon y los danzantes formaron un círculo a su alrededor. Y retomaron todos una especie de melodía lúgubre. Una melodía de remordimiento, de contrición religiosa, llamada secreta de no sé qué fuerzas oscuras, de qué presencias del más allá. Fueron enseguida a sentarse delante de un gran fuego situado más lejos, en un lugar cubierto y cerrado como la misma noche, pues la segunda parte del rito debía demostrar que era oculto. En este momento, les dieron la sangre viva, servida en copas. Y la danza recomenzó desde el principio... Que se piense lo que se quiera sobre la relación que hago. En todo caso, como Platón nunca fue a México y los Indios Tarahumaras nunca lo vieron, hay que admitir que la 
idea de este rito sagrado les llegó de la misma fuerza fabulosa y prehistórica. $Y$ es lo que he querido sugerir aquí» (O.C. IX, 72-76).

- Mención de Platón y del mito de la Atlántida, en carta a Jean Paulhan, 4 de febrero de 1937, relativa a los Tarahumaras: «...esta forma de la $\mathrm{H}$ que parece resultar [de las edificaciones tarahumaras] es la figura central sobre la que Platón cuenta que los Atlantes habían construido sus ciudades; si uno quiere, es cosa pueril, pero esto existe en la montaña Tarahumara y en Platón» (O.C. IX, 102).

- Referencia tardía a los filósofos neoplatónicos Plotino, Yámblico, Porfirio y a Filón de Alejandría, así como a su visión de los daimones, en una carta al doctor Gaston Ferdière, 29 de marzo de 1943, firmada por Artaud con el pseudónimo de «Antonin Nalpas». Se trata de las reflexiones del poeta sobre un libro que le había procurado el doctor Ferdière, el Hymne aux Daimons de Pierre de Ronsard, místico platonizante francés del siglo XVI, posiblemente la edición de A.-M. Schmidt publicada en Albin Michel en 1938, según la edición Gallimard. Según Platón los daimones son seres intermedios entre los hombres y los dioses, con características de ambos. Los filósofos neoplatónicos y neopitagóricos asumieron esta definición y consideraron que los daimones tienen diversos grados según su proximidad a la perfección divina o a la imperfección humana. El pensamiento del neoplatónico Plotino (205-270 d.C.) es uno de los más profundos y complejos de la Antigüedad. Para este filósofo, el hombre es un momento particular del «Anima» universal, la cual, junto al «Uno» y el «Espíritu», forman las tres hipóstasis que dan origen a lo incorpóreo; el fin del hombre es retornar al absoluto despojándose de las adherencias del cuerpo y también del «Anima». Porfirio (233/4 - 305 d.C.) atemperó la doctrina de Plotino, volviendo a posiciones medioplatónicas; pone en primer plano el componente ético, subrayando la ascesis del individuo hacia Dios a través del «Ánima». Filón de Alejandría, filósofo judío (25 a.C.-40 d.C.), trata de complementar el pensamiento bíblico con la filosofía platónica. Para Filón, Dios es completamente trascendente a la creación del mundo; esta separación se llena con seres intermediarios entre los que destaca el Logos, instrumento divino de la creación. El fin del hombre es la unión con Dios mediante una ascesis gradual del mundo de la materia y de las pasiones. Por su parte, Artaud habla de su metafísica pagana en un contexto de ideas cristianas (el poeta había sido internado con delirio religioso): «Ronsard ha hecho Magia y él era iniciado y cada verso de su poema es un reflejo de esta iniciación trascendental. Esta iniciación es misteriosa... El Hymne des Daimons de Ronsard traduce, de cerca, la Historia de este desarrollo y de este desenvolvimiento de la Potencia en las esferas y de todos los peligros de la pérdida de la Potencia en las esferas y de la lucha oculta del cielo contra las malas tentaciones de la Potencia, y de las formas vivientes un instante pero condenadas que resultan de ello perpetuamente, pero que se detienen finalmente, 
como dice Ronsard, con los rayos del Juicio. Los daimones son entidades provisionales y no vivientes pero animadas por imitación y como los dobles de los movimientos verdaderos y de las órdenes verdaderas del creador en las esferas. Pues, en efecto, los espacios están habitados por seres, pero estos seres son todos Ángeles de mayor o menor dimensión, y de un lugar mayor o menor, pero para cada uno de ellos infinito, absoluto y total en lo que le concierne a la mirada del Eterno. En el tiempo en que filósofos como Plotino, Yámblico, Porfirio o Filón han hablado de los daimones, sólo se trata de la Transformación de un Ángel animándose de sí mismo, que aprende a ser amando, y que se anima amando el alma de cualquier vida. Pues incluso los dobles de las cosas deben remontar hasta el alma de su Potencia y de su Movimiento. Dios ha dado el Movimiento y el Alma, pero cada ser, a su vez, ha debido merecer serlo y para serlo, vivir su vida en límites extremos de su comienzo y participar así en la creación de su alma... Creo saber que Ronsard, que era católico y muy cristiano, tenía como poeta una misión en la Tierra y esta Misión sagrada es volver a decir, en un lenguaje que habla al corazón, el bien de las cosas del Infinito, que son mágicas y misteriosas en esencia» (O.C. X, 24, 26-28). Según A.-M. Schmidt, editor de Ronsard, éste da a su pensamiento la forma de una síntesis nueva de las teorías demonológicas de sus predecesores, pero no se refiere, en todos los casos, a las alegaciones originales, sino que las utiliza para cristalizar sus ideas personales. A pesar del orden natural de su espíritu, Ronsard no llega a unificar completamente sus concepciones. Hay tres nociones casi antagonistas del universo demoníaco: 1) la noción antigua, que tiene a los daimones por criaturas intermedias entre lo humano y lo divino, y que no les atribuye una malicia esencial; 2) la noción cristiana, para la cual los daimones son totalmente malos y sediciosos; 3) la noción popular, que, más práctica que teórica, trata de armar a los hombres contra sus tentativas. La exposición de Ronsard, concluye Schmidt, obedece a las mismas influencias que un Agripa o un Paracelso, epígonos del platonismo florentino... (A.-M. Schmidt, «Avant-propos», pp. 5-6). Por otro lado, en una Nota al final de esta carta dirigida al Dr. Ferdière, Artaud cita al místico Ramón Llul: « Hay un libro en el que he pensado mucho escribiendo esta carta. Es el Libro de Amigo y Amado [Libre d'amich e amaf] de Ramón Llul, porque hay una cosa en la que he pensado mucho: es la lucha singular en cada uno de nosotros que opone en cada uno de nosotros durante un instante, el espíritu y el alma pero para confundirlos y probarlos mejor después de que sean una sola y misma cosa porque los dos vienen de una cosa única, el Ser que está en nosotros y que es nosotros. Como el Ser en lo que tiene de particular y de singular viene de una causa universal que es Dios. Muchos Ángeles han quedado como Seres un tiempo y en el tiempo antes de librarse a la Consumación Universal de Dios, de igual modo ha pasado un tiempo antes de que los dos fuegos conjuntos y oponibles en un momento, del espíritu y del alma, se hayan librado a la consumación universal 
del ser y de todos los Seres en Dios, resolviendo antes esta oposición abisal oculta que separa las facultades del yo a fin de unirlas mejor en un amor común y esto no puede ser el amor de Dios en sí que se traduce en el olvido de sí mismo con el respeto de sí mismo que es respetar al Espíritu de Dios en sí» (O.C. X, 30-31). Ramón Llul, erudito, filósofo, teólogo y poeta mallorquín (1235-1315), estuvo influenciado por el neoplatonismo de Escoto Eriugena (especialmente, el De divisione naturae) y por el neoplatonismo agustiniano de los filósofos y teólogos «victorianos». Para Llul, la experiencia mística es una purificación progresiva para llegar a una unión amorosa final, en la que el hombre y Dios, sin embargo, quedan como cosas distintas.

- Referencia tardía al Eros platónico en una carta a su madre, Mme. Artaud, enviada desde Rodez el 5 de agosto de 1944: «Platón ha intentado dar una idea sublime del amor en sus libros; su doctrina, que es maravillosa, ha servido para componer en nuestra lengua la expresión famosa del amor platónico que quiere decir para los franceses amor que no existe» (O.C. X, 253).

- Referencia tardía a Platón, en relación con Empédocles y Sócrates, en el fragmento «ll n'y a ni principe ni être...», escrito en mayo de 1945: «Platón, Empédocles, Socrates, / en el lavabo de un dancing» (O.C. XVI, 39).

- Comparación tardía de la teoría de las ideas platónica con las «ideas» de la época de Artaud en el fragmento «ll y a dans notre époque...», escrito en la segunda quincena de agosto de 1946: «Hay en nuestra época algo más, digo, más hondo aún que este viejo criminal sucio de Platón, y también algo menos. // Cuando uno no tiene otra idea que hacer vivir a las ideas por ellas mismas, y trabajar para separarlas de los seres y de los cuerpos que podrían haberlas llevado quizás y que, en todo caso, las han visto. Cuando uno no tiene otra idea que aislar una idea en sí y en su principio y separarla como un higo en su punto, del ser y de su condición, / cuando uno cree en esta cosa cualquiera que es una idea, / cuando uno quiere ver las ideas sin cuerpo, / y fuera del órgano de la visión, / y como una especie de revelación, / y entonces el principio habla a lo increado, / ... // no hay nada, exactamente nada, y uno se hunde. // Pensando en ello, algo se ha separado de la idea de Platón y ha dicho: / No lo hagas. // Cuando uno cree en ideas principios que viven fuera de los cuerpos constituidos, ... // cuando uno cree en ideas, en ideas principios vivas / pero fuera de un cuerpo constituido (viviendo sólo de la idea), / no teniendo de vida nada más que la idea, / pues hay ideas totémicas vivientes, / ELLAS viviendo en un cuerpo constituido, pero no es lo que Platón buscaba...» (O.C. XXIII, 102).

- Referencia a las ideas de Platón en el fragmento «ll y eut un homme en effet crucifié...», escrito en agosto de 1946: «Jesucristo es esa fuerza conjunción de una de las posiciones imbéciles más antiguas de la humanidad... 
/ A saber, que el espíritu sobrevive al cuerpo y que todos los pecados del cuerpo nunca han mermado de cerca la fuerza de una idea luz / porque la idea es lo que sobrevive sin cuerpo - / dios es un puro espíritu, avanza la ortodoxia cristiana pura, pero no es ella la que ha dicho: el hijo del Hombre este Jesucristo. / Platón también dio en este defecto con su idea secularizada de la caverna de las ideas, / es así como a fuerza de soñarlo los sacerdotes han hecho de esta idea de Jesucristo un ser, que hace 2 mil años no había existido / pero que pensaba" (O.C. XXIII, 128).

- Referencia a Platón en el fragmento «La conscience est aux mains...», escrito entre el 29 de diciembre de 1946 y el 13 de enero de 1947, fecha de publicación de Histoire vécue d'Artaud-Mômo, obra de la que constituye un texto preparatorio: «Hay embrujamientos, // la innoble pudibundez de orgullo impide reconocerlo, / pero es así. // Es una especie de secreto que han visto algunos raros poetas, / Villon, Baudelaire, Gérard de Nerval, Edgar Poe, Nietzsche / lo habían presentido, / los filósofos confusamente, Platón, estos llamados hermetistas» (O.C. XXVI, 106).

- Referencia tardía a Platón en el fragmento «Es-prit», escrito a finales de enero de 1947 o poco después, texto que forma parte de Suppôts et Suppliciations, recopilación de textos acabada el 21 de febrero de 1947: «Pues no es ordinario babear sobre las gentes en espíritu para imponerles el Decálogo. // Y así es como han procedido siempre todos los iniciados, / de Platón a Empédocles, / pasando por Buda y Çâika-Mouni. // Han batido su esperma de espíritu sobre toda la extensión de la conciencia, para imponerle sus Instituciones» (O.C. XIV/2, 125).

En conclusión, Artaud encuentra en la filosofía de Platón uno de los fundamentos de su metafísica de la «crueldad» cósmica. Retiene del Platonismo y del Neoplatonismo la noción de "potencia» en el devenir, es decir la presencia de fuerzas invisibles con las que el hombre puede entrar en relación, como los diosesprincipios (los cuales se manifiestan en los cultos órficos y en los misterios de Eléusis) y los daimones. Asimismo, Artaud menciona varios temas platónicos: la teoría de las ideas y el mito de la caverna (ideas-principios), el mito de la Atlántida (una raza-principio de iniciados) y el Eros (espíritu) contrapuesto a la libido (materia). 